\title{
Programas de subvenção às atividades de PDI: uma comparação em biocombustíveis no Brasil, EUA e Europa
}

Felipe dos Santos Pereira*

Jose Vitor Bomtempo**

Flavia Chaves Alves***

RESUMO

Entre os instrumentos de política pública disponíveis, encontra-se o apoio direto com recursos públicos a projetos de pesquisa e desenvolvimento executados no âmbito das empresas. Tais instrumentos, denominados comumente por grants ou subvenção econômica, exigem capacidade do poder público para especificar o foco temático de apoio, bem como para selecionar os projetos de interesse e acompanhá-los. A efetividade de programas públicos desta natureza depende do modo como as instituições públicas responsáveis pela administração dos recursos realizam suas escolhas, o que é reflexo dos processos instaurados internamente nestas organizações. Este artigo propõe um quadro analítico para comparação dos programas públicos de apoio, com foco nos processos de formulação, seleção e acompanhamento de projetos. Para tanto, são caracterizados três casos recentes de apoio desta natureza: o Biomass Program, nos EUA; o Paiss, no Brasil; e o NER300, na Comunidade Europeia. Verifica-se que o efeito de

* Universidade Federal do Rio de Janeiro (UFRJ), Rio de Janeiro (RJ), Brasil. E-mail: felipe.s.per@hotmail.com

** Universidade Federal do Rio de Janeiro (UFRJ), Rio de Janeiro (RJ), Brasil. E-mail: vitor@eq.ufrj.br

*** Universidade Federal do Rio de Janeiro (UFRJ), Rio de Janeiro (RJ), Brasil. E-mail: falves@eq.ufrj.br 
disparo de corridas tecnológicas está relacionado com maior empenho de conteúdo tecnológico e de engenharia aos processos, por parte da administração pública.

PALAVRAS-CHAVE | Inovação; Política Tecnológica; Subsídios; Subvenção Econômica; Efetividade

Códigos JEL: | O38; L52; O25

\section{R\&D grant programs as industrial policy: comparing Brazil, US and Europe within biofuels sector}

Direct public support for research and development projects performed within firms is one of the policy instruments available. These instruments, commonly known by grants, require ability of government to specify the thematic focus of support as well as to select projects of interest and follow them. The effectiveness of public programs of this nature depends on how the public institutions responsible for resource management execute their choices, which is a reflection of the internal processes that take place in these organizations. This article proposes an analytical framework focused on the main processes of formulation, project selection and monitoring. Then, it describes three recent cases: Biomass Program in U.S., PAISS in Brazil, and NER300 in the European Community. It appears that the effect of triggering technological races is associated with a greater commitment to technological and engineering content from the government side.

KeYwords | Innovation; Technology Policy; Subsidies; Grants; Effectiveness

JEL-CODES: | O38; L52; O25 


\section{Introdução}

No setor de biocombustíveis, as políticas públicas adotadas nos EUA e na Europa dispararam uma verdadeira corrida tecnológica nas últimas décadas, capaz de criar inúmeras empresas de base tecnológica, com propostas absolutamente inéditas em relação ao processo de conversão de biomassa em combustíveis, ao tipo de cultura agrícola e solução logística para garantir a disponibilidade da matéria-prima e às propostas de novas moléculas (ex: butanol, farneseno hidrogenado, etc.), capazes de atender aos critérios de alto conteúdo energético e eficiência de queima sem necessidade de substituição da infraestrutura de distribuição (combustíveis avançados).

A estruturação dessas políticas é particularmente notável, no caso norte-americano, pelo Department of Energy (DOE) e do Department of Agriculture (USDA) e, no caso europeu, pelas diversas iniciativas da Comissão Europeia. No Brasil, a iniciativa conjunta BNDES/Finep, conhecida como Paiss, deslanchada a partir de 2010, pode ser vista como a versão brasileira mais bem estruturada, até agora, em políticas de inovação para a bioeconomia. Há estudos em andamento sobre a diversificação da indústria química (BNDES) e sobre as tecnologias prioritárias em química renovável (ABDI/CGEE, dentro do Programa Brasil Maior), mas não resultaram ainda em iniciativas concretas de políticas de inovação.

Tais políticas incluem basicamente dois tipos de mecanismos que influenciam nas mudanças tecnológicas: os de promoção da demanda (demand-pull) e os de alavancagem da ciência e da tecnologia (technology-push). Entre estes possíveis incentivos, há os de natureza fiscal, que se baseiam em reduções na carga tributária incidente sobre empresas inovadoras, os de formação de mercado, que buscam estimular a demanda por inovaçôes e assim reduzir as incertezas de mercado, e o apoio direto do governo via subvenção econômica.

Os programas de subvenção econômica no Brasil, operacionalizados pela Agência Brasileira de Inovação (Finep), mobilizam recursos com magnitude inferior aos programas análogos nos EUA e na Europa. As fases pré-competitivas de escalonamento industrial para construção de unidades-piloto e de demonstração da viabilidade comercial, no âmbito da empresa, tão essenciais na corrida tecnológica dos biocombustíveis e da química renovável, são onerosas e de alto risco. Estas etapas do ciclo de $\mathrm{P} \& \mathrm{D}$ não encontram, no Brasil, as mesmas benesses públicas observadas nos programas de governo nos EUA e Europa, ao menos no que se refere aos programas de apoio direto via subvenção econômica. 
Apesar deste reconhecimento, será que o mero incremento orçamentário das agências públicas brasileiras responsáveis pela administração da subvenção econômica é um fator suficiente para se alcançar a efetividade desejada? A eliminação de barreiras quanto ao uso do recurso, ampliando sua alocação para despesas de capital e permitindo o apoio público direto à construção de ativos privados destinados a testes-piloto e de demonstração, por si só, traria ganhos de competitividade, no quesito tecnológico? A mobilização de recursos públicos adicionais traria alguma mudança na trajetória de empresas brasileiras?

Este artigo propóe-se a caracterizar e comparar os processos de formulação e execução de mecanismos de incentivos financeiros diretos na modalidade não reembolsável (subvenção econômica ou grants) destinados à fase de pesquisa pré-competitiva no âmbito das empresas, usando como casos as experiências recentes da corrida tecnológica em busca dos combustíveis avançados e outros bioprodutos nos EUA, Europa e Brasil.

Assim, a seguir, são apresentadas as visões de efetividade (impacto) de programas públicos de apoio direto a PDI privado, por meio de subvenção, bem como o quadro analítico utilizado na comparação entre os casos selecionados. Posteriormente, descrevem-se as principais características dos programas norte-americano, brasileiro e europeu, analisando-os à luz do quadro analítico. Por fim, são tecidas as conclusões do estudo.

\section{Avaliação de impacto do apoio público direto a projetos privados de P\&DI}

Estudos prévios revelam que não há um consenso sobre a efetividade de programas de subsídios públicos diretos a atividades de P\&D no âmbito da empresa. As evidências de efetividade de subsídios diretos são modestas e controversas. David et al. (2000) realizaram extensa revisão na literatura e concluíram que, em um terço de todos os programas avaliados, há efeito de simples substituição do orçamento privado por recursos públicos, sem alavancagem real de projetos com retorno social. Métodos de avaliação com diferentes abordagens econométricas têm sido propostos, mas existe uma lacuna no que se refere à sistemática de avaliação (GONZÁLEZ; PAZÓ, 2008).

No entanto, a maioria dos autores concorda que a efetividade dos programas de apoio público direto depende, entre outros fatores, das competências e habilidades de burocratas do governo em formular programas, selecionar projetos e acompanhá-los (CLAUSEN, 2009; STEINMUELLER, 2010). Ou seja, o simples incremento de 
recursos públicos destinados ao apoio direto a projetos de alto risco não configura uma condição suficiente de efetividade, qual seja: a realização de projetos que não seriam feitos caso o recurso público não estivesse disponível e que tragam, se bem-sucedidos, alto retorno social.

Um conceito central encontrado na literatura é o que propõe a motivação para as políticas de apoio público direto a atividades de P\&D nas empresas. A teoria indica que os investimentos privados em $\mathrm{P} \& \mathrm{D}$ são inferiores ao ótimo devido a falhas de mercado associadas à alocação de recursos privados em atividades de inovação (GONZÁLEZ; PAZÓ 2008; CLAUSEN, 2009). A presença de externalidades positivas acarreta descasamento entre os níveis de retorno privado e social para essas atividades, de modo que as empresas investem menos em P\&D do que o que seria o "ótimo social". Esta é uma teoria originalmente introduzida por Arrow (1962), que aponta que a dificuldade de apropriabilidade dos resultados do P\&D pela empresa reduz suas chances de retorno, aumentando o descasamento entre os interesses privado e social em projetos de $\mathrm{P} \& \mathrm{D}$. A intervenção pública busca resolver este problema.

No entanto, fartos são os estudos que concluem divergentemente sobre a efetividade do apoio público direto a P\&D privado, ou seja, no poder de indução de desenvolvimento tecnológico que este tipo de mecanismo pode alcançar (GRETZ et. al., 2012; FORAY et. al., 2012). Por um lado, diferentes visões de efetividade (ou impacto) podem contribuir para sua qualificação final e, portanto, para declaração de sucesso ou fracasso de certo programa. Assim, metodologias que se propõem a avaliar adicionalidades de input (como alavancagem de P\&D privado), de output (como receita com novos produtos), ou comportamental (ligada à aprendizagem da empresa) são enfoques diferentes que, em geral, levam a conclusões distintas (BUSOM, 2008; CLARYSSE et al., 2009; WANZENBÖCK et al., 2012).

Por outro lado, a mensuração de efeitos considerados indesejados (efeitos colaterais) na metodologia de avaliação de impacto também pode ter influência nas conclusões sobre a efetividade do programa. Citam-se, por exemplo: o aumento da concentração industrial por meio do aumento da barreira de entrada - uma vez que empresas estabelecidas possuem maior capacidade de postular recursos públicos (LAINCZ, 2009); o favorecimento a grandes empresas e a projetos maduros, com baixo risco tecnológico, em detrimento de projetos com maior potencial de retorno social (CANTNER; KÖSTERS, 2012; GUISADO-GONZÁLEZ et al., 2013); ou mesmo efeitos de crowd-out, nos quais se observa a substituição de fontes em projetos que já seriam executados pelas empresas mesmo que o programa público 
de apoio não estivesse disponível (GONZÁLEZ; PAZÓ, 2008; CLAUSEN, 2009; CZARNITZKI; LOPES-BENTO, 2012).

Não obstante, cabe ressaltar que a maioria dos estudos disponíveis na literatura concentra seu foco na mensuração de efeitos de "input" ou "output" (a própria indução de mudança comportamental pelas empresas apoiadas não deixa ser um "output" do programa). Aspectos institucionais, internos aos órgãos públicos responsáveis por formular, executar e acompanhar os programas, são virtualmente negligenciados pelos estudos de avaliação de impacto de programas desta natureza. ${ }^{1}$

Diferentemente, neste artigo, elaborou-se um quadro analítico que permite a comparação entre três diferentes programas que concederam subvenção (grants) a empresas com projetos de desenvolvimento de novas rotas tecnológicas para conversão de biomassa em biocombustíveis. O ponto central dos critérios desenvolvidos foi tratar dos processos praticados pelas agências e não apenas as entradas (recursos aplicados) e saídas (resultados obtidos). Em última análise, a qualidade dos projetos selecionados para apoio (e, portanto, de sua efetividade em termos de entradas e saídas) é influenciada pelos processos de formulação do programa, seleção e acompanhamento dos projetos, instaurado em suas agências executoras.

O Quadro 1 apresenta a comparação dos três programas aqui analisados $\mathrm{Na}$ estrutura dos programas foram pesquisadas e comparadas sete variáveis: orçamento do programa; intensidade do apoio por projeto; tipologia de apoio (cost-sharing $\mathrm{x}$ reward for performance); subordinação hierárquica ao governo central; fases de P\&D passíveis de apoio, objetivos (explícitos e implícitos); e integração com outros instrumentos de apoio financeiro. No estudo dos processos de formulação, seleção e acompanhamento, cinco variáveis foram pesquisadas e comparadas: nível de aprofundamento tecnológico na fase de formulação; nível de envolvimento da comunidade científica na fase de formulação; quesitos classificatórios aplicados à fase seletiva; nível de profundidade da avaliação tecnológica (fase de seleção); e foco das rotinas de acompanhamento e avaliação.

1 Para discussão mais profunda sobre capacitaçôes da administração pública para formular e executar programas públicos de promoção a ciência e tecnologia, consultar Steinmueller (2010) e Pereira (2013). 


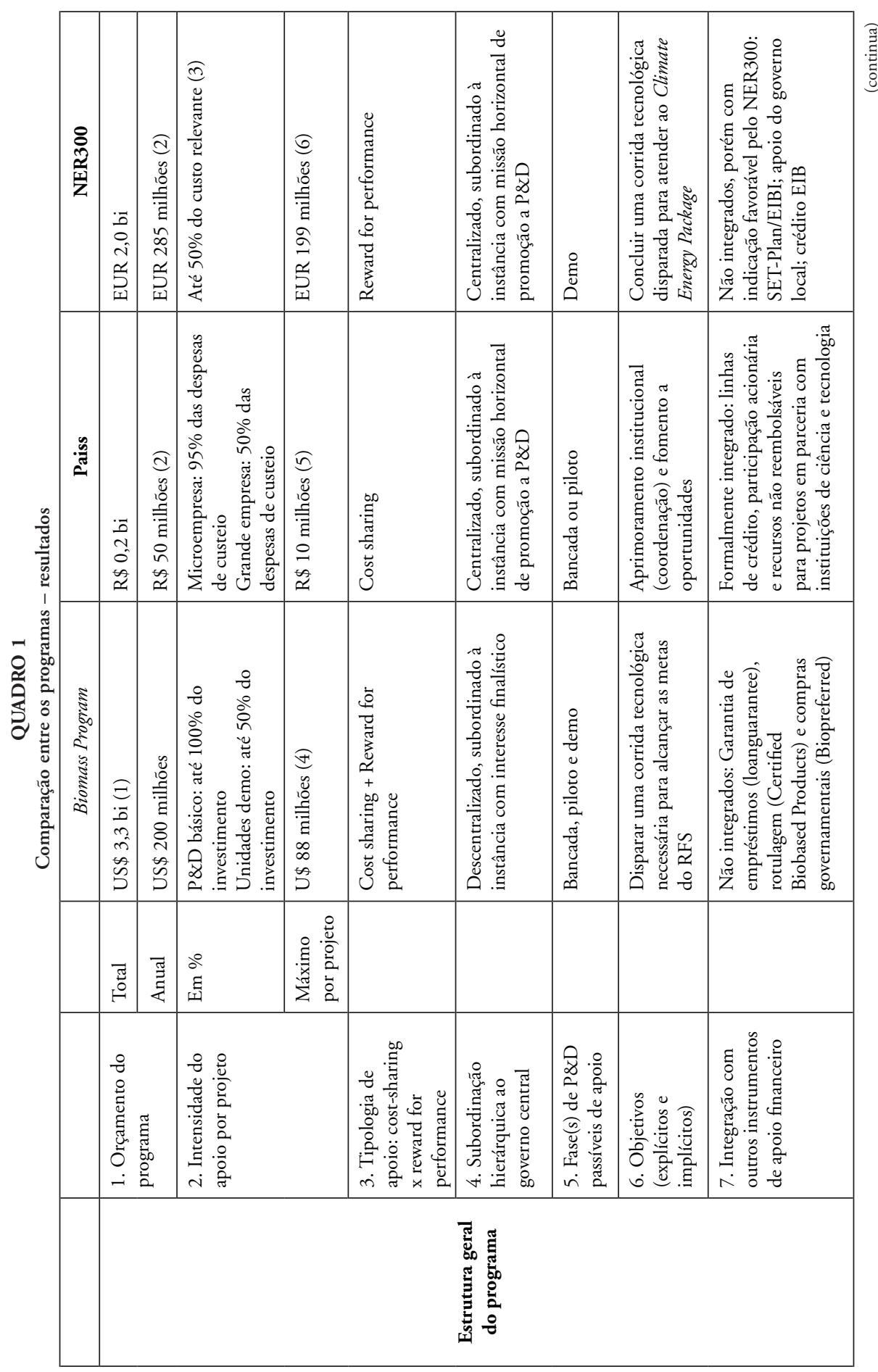




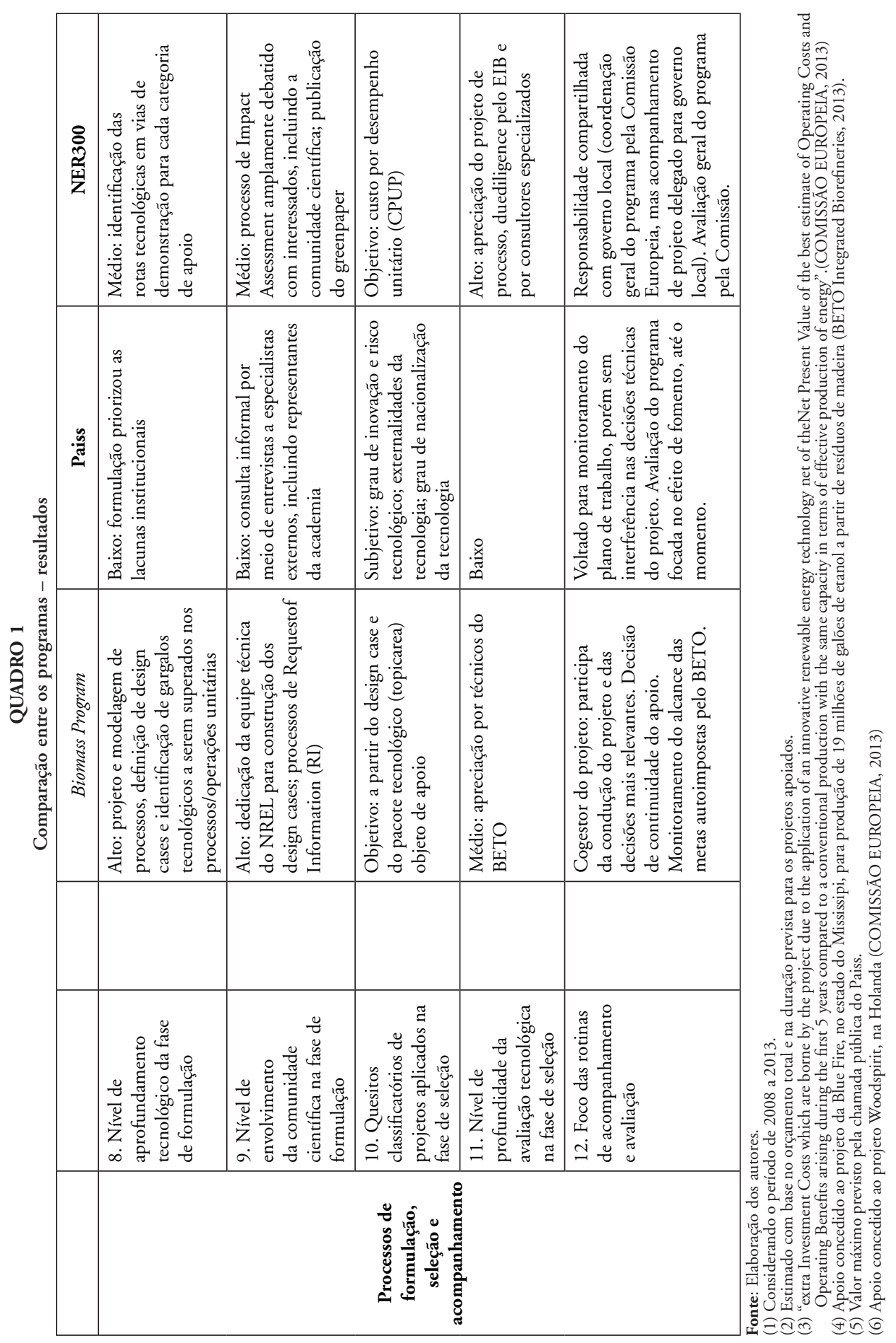




\section{Comparação entre os programas do Brasil, EUA e Europa}

Os programas selecionados para comparação foram: o Biomass Program (EUA), o Paiss (Brasil) e o NER300 (Europa), considerando-se sua aderência temática aos biocombustíveis avançados, bem como a magnitude do recurso público alocado. As informaçôes foram levantadas a partir de acesso ao conteúdo oficial disponível no endereço eletrônico das agências estudadas e órgãos do governo, além de artigos e publicaçóes de terceiros sobre o tema. Nos casos do Paiss e do Biomass Program, também foram utilizadas fontes primárias de informação, por meio de entrevistas com representantes das agências executoras e de órgãos de governo, com duração total aproximada de 12 horas.

Esta seção está organizada da seguinte forma: primeiramente, são apresentados os programas, seu contexto de criação e magnitude. Em seguida, são analisados seus aspectos estruturais considerados mais relevantes e, finalmente, discutem-se as dimensões dos processos internos de formulação, seleção e acompanhamento dos projetos.

\subsection{Apresentação dos programas}

Nos EUA, o principal programa de apoio financeiro direto à bioeconomia é o Biomass Program, patrocinado e operacionalizado pelo Departamento de Energia (DOE), contando com orçamento anual de cerca de US\$ 200 milhões. O programa nasceu na década de 1970, mas suas missões atuais foram definidas em 2008, em resposta ao Renewable Fuel Standard (RFS), política que estabelece mandato crescente de uso de biocombustíveis de alto desempenho nos EUA. Desde 2008, estima-se que seu orçamento acumulou cerca de US\$ 3.300 milhôes. O programa propõe-se a apoiar projetos em diferentes fases de P\&D: bancada, piloto e demonstração. O registro de maior apoio a um único projeto é de US\$ 88 milhões.

No Brasil, a principal fonte de incentivo financeiro direto é a Financiadora de Estudos e Projetos (Finep). Em 2011, a Finep e o Banco Nacional de Desenvolvimento Econômico e Social (BNDES) lançaram o Programa de Apoio ao Desenvolvimento Tecnológico Industrial dos Setores Sucroenergético e Sucroquímico (Paiss). O plano foi uma resposta ao diagnóstico de que, no Brasil, os programas de apoio a esses setores tinham como característica a baixa coordenação das agências públicas nas atividades de fomento e apoio com recursos públicos, além do pequeno volume de recursos alocados (NYKO et al., 2010). Entre os diferentes instrumentos de apoio colocados à disposição das empresas postulantes, o Paiss reservou R \$ 200 milhões 
para apoio direto, via subvenção, a serem desembolsados em um horizonte de quatro anos. Os recursos de subvenção foram utilizados para apoio a projetos nas fases de bancada ou piloto, com valor máximo de $\mathrm{R} \$ 10$ milhões por projeto, limitando-se, porém, a despesas de custeio (PAISS CHAMADA PÚBLICA, 2011).

$\mathrm{Na}$ Europa, destaca-se o programa intitulado NER300, que se baseia no "Emission Trade System (EU ETS)" ou "capand trade", mecanismo destinado a ajudar os Estados-membro da Comunidade Europeia a cumprir suas metas de emissão de gases de efeito estufa (GEE) no contexto do Protocolo de Kyoto. O mecanismo europeu prevê recursos de leilóes das novas autorizações de cotas de emissão de GEE (ou New Entrants Reserve - NER) para incentivar, com apoio direto via grants, projetos de unidades de demonstração de tecnologias inovadoras para Geração de Energia Renovável (RES) e para Captura e Armazenamento de Carbono (CCS). Estima-se em EUR 2 bilhões o orçamento total do NER300. O maior apoio a um único projeto contemplou EUR 199 milhões.

\subsection{Dimensões estruturais dos programas}

Esta seção apresenta as principais dimensões estruturais dos programas, de acordo com a proposta do quadro analítico (Quadro 1). As variáveis "tipologia do apoio", "subordinação hierárquica ao governo central" e "objetivos (explícitos e implícitos) dos programas" foram analisadas em detalhe. As demais dimensões estruturais do quadro analítico - magnitude do orçamento, intensidade e fase do apoio e integração com outros instrumentos - foram resumidas na seção 3.1 por apresentarem caráter mais descritivo.

\section{Tipologia de apoio: cost-sharing $x$ reward for performance}

De acordo com a classificação apresentada por Gretz et al. (2012), com relação aos tipos de estrutura dos programas públicos de subsídio a P\&D privado, pode-se verificar a distinção de abordagem entre os programas aqui estudados.

O modelo brasileiro poderia ser enquadrado na classificação cost-sharing, uma vez que as despesas do projeto são rateadas entre a empresa e o governo, independentemente dos resultados do projeto. Com efeito, é neste esquema de apoio que se observa maior compartilhamento de riscos do investimento privado pelo setor público, já que os casos de fracasso, naturais das incertezas tecnológicas de projetos desta natureza, não são penalizados com suspensão do apoio. 
Por outro lado, o programa europeu se baseia no conceito de reward for performance. Neste caso, a liberação do recurso público é condicionada ao cumprimento de metas para indicadores de desempenho claramente estabelecidos $a$ priori. Se o projeto não alcançar tais metas, o apoio é reduzido, ou integralmente suspenso, ainda que o projeto em questão tenha sido positivamente apreciado na etapa seletiva do programa, em geral concorrida e exigente. Trata-se, nesta situação, de uma opção de apoio que incentiva o cumprimento de metas tecnológicas, de modo muito pragmático. Poder-se-ia deduzir que, nesta modalidade, o postulante do apoio público teria maior interesse em atingir as metas de desempenho, já que no modelo de cost-sharing o progresso físico do projeto não é fundamental para a manutenção dos mecanismos de apoio do governo. No limite, este modo de apoio parece ser capaz de disparar com maior eficácia a corrida tecnológica demandada pela sociedade. No entanto, críticos desta modalidade argumentam que ela traz inconsistências em sua concepção e apresenta menor retorno social do que o modelo de cost-sharing (GRETZ et al., 2012).

Já o programa norte-americano opta, nesta ótica, por um modelo híbrido de apoio. Ao prever marcos (gates) de avaliação dos projetos, com indicadores de desempenho e metas previamente estabelecidas na etapa de formulação e seleção, a equipe de acompanhamento pode decidir por interromper ou continuar o apoio ao referido projeto. Neste sentido, o alcance das metas seria uma espécie de recompensa por desempenho (reward for performance), na medida em que, ao fazê-lo, o beneficiário se torna elegível para ser apoiado nas fases seguintes do projeto. Porém, os recursos públicos já invertidos até o momento da avaliação não precisam ser estornados, o que confere ao programa a característica de cost-sharing. Ou seja, pode-se dizer que a tipologia do Biomass Program admite ambas as abordagens, simultaneamente.

\section{Subordinação hierárquica ao governo central}

É curioso observar as diferenças na linha de comando das organizações responsáveis pela execução dos programas de apoio aqui estudados. A subordinação hierárquica entre os formuladores/executores dos programas e seus ascendentes no organograma do poder público ajuda a demonstrar o nível de envolvimento dos interessados finalísticos, por parte do governo, no efetivo disparo da corrida tecnológica.

No caso norte-americano, o Biomass Program é conduzido pelo Bioenergy Technologies Office (BETO), órgão subordinado ao Departamento de Energia (DOE), que é a instância máxima de governo responsável pela política energética do país. De 
modo a viabilizar as diretrizes de segurança e a independência energética dos EUA, o DOE é o protagonista na promoção de tecnologias que viabilizem economicamente as fontes alternativas de energia, entre elas a biomassa. No amplo conjunto de instrumentos criados para esta finalidade, destaca-se o Renewable Fuel Standard (RFS), mandato que obriga as operadoras de combustíveis nos EUA a utilizarem parcelas crescentes de biocombustíveis com baixa emissão de GEE, e cujo monitoramento e controle cabe justamente ao DOE. Por isso, a opção norte-americana reflete a consciência de que é necessário desenvolver tecnologias viabilizadoras deste mandato, e que cabe, sobretudo ao DOE, esta missão. Ou seja, a agenda de inovação tecnológica do setor não é delegada a outra instância ministerial, mas sim mantida sobre sua própria coordenação. O governo dos EUA sequer possui uma instância dedicada ao tema de ciência, tecnologia e inovação, tampouco ao de desenvolvimento industrial. Com isso, as demandas tecnológicas de cada setor tendem a ser mais bem especificadas, e os programas de apoio mais focados e pragmáticos.

Por outro lado, a opção de organização do governo nos casos europeu e brasileiro atribui a uma instância centralizada a missão de elaborar, formular e executar políticas públicas de pesquisa, desenvolvimento e inovação. No caso da Europa, esta atribuição é, na realidade, ainda mais extensa, uma vez que a Comissão Europeia tem a prerrogativa de iniciar qualquer processo de formulação e proposição de políticas públicas, não apenas para $\mathrm{P} \& \mathrm{D}$.

No caso do Brasil, o Ministério de Ciência, Tecnologia e Inovação (MCTI) é o principal responsável pelas políticas de P\&D no país, com atuação em diversos setores da economia, notadamente por meio de sua agência de inovação, a Finep. Além disso, o Ministério de Desenvolvimento, Indústria e Comércio (MDIC), reconhecendo a importância da inovação para a competitividade da indústria nacional, também tem apresentado propostas de instrumentos de apoio a inovação, notadamente pelo BNDES.

\section{Objetivos (explícitos e implícitos) dos programas}

Observa-se que as justificativas oficiais dos três programas analisados incluem, entre outros, um objetivo comum: promover o desenvolvimento de novas tecnologias industriais, que possam alcançar viabilidade econômica, no campo dos biocombustíveis de alto desempenho. No entanto, algumas particularidades podem ser destacadas. 
No caso dos programas norte-americano e europeu, nota-se em sua formulação a intenção deliberada de viabilizar os mandatos de uso de biocombustíveis, como medida para redução da emissão de GEE, como o RFS nos EUA e o Climate Energy Package na Comunidade Europeia. Ou seja, o esforço público nestes casos é uma resposta natural ao mandato imposto pelo próprio governo, e este constituiu o principal driver para a formulação dos programas. Cabe ainda ressaltar que as tecnologias disponíveis não permitiam (como ainda não permitem) cumprir os mandatos. Assim, uma corrida tecnológica precisava ser disparada. O desenvolvimento de tecnologias que viabilizam um desejo da sociedade (transformado em mandatos) poderia ser comparado com o conceito de "projetos orientados a missão" (FORAY et al., 2012), definidos como aqueles cujos objetivos e metas específicos são ditados pelo setor público e lançados aos postulantes privados, no intuito de romper uma fronteira tecnológica bem caracterizada.

Assim, no caso do Biomass Program, poderia ser dito que seu principal objetivo foi disparar uma corrida tecnológica necessária para o alcance das metas definidas no RFS. Já para o NER300, como seu foco de apoio se concentrou na etapa de demonstração, final do ciclo de desenvolvimento, seu principal objetivo foi o de concluir uma corrida tecnológica disparada previamente para atender ao Climate Energy Package.

Já no caso brasileiro, a reconhecida experiência do setor sucroalcooleiro, o uso do etanol como combustível veicular e, sobretudo, o recente incremento da frota de motores flexfuel colocam o país em posição de destaque internacional no uso de combustíveis renováveis. Esta condição, que faz com que a participação atual dos biocombustíveis na frota brasileira já supere as metas dos mandatos dos EUA e da Europa impostas para 2020, leva à ausência de políticas públicas mais ousadas que visem ampliar a participação do mercado de biocombustíveis no país. Como reflexo, não há, no Brasil, uma política de mandatos em marcha crescente como se observa nos EUA e na Europa. Por outro lado, vislumbra-se no setor sucroalcooleiro uma oportunidade de aproveitamento do potencial de seus resíduos, como o bagaço e a palha, para incrementar a produção de etanol, por meio do uso de tecnologias inovadoras. Ou seja, o principal motivador para a formulação do Paiss não foi essencialmente disparar uma corrida tecnológica, mas sim aproveitar uma janela de oportunidade bem identificada de potenciais sinergias entre o setor sucroalcooleiro nacional e a aplicação de tecnologias que estavam em franco desenvolvimento no exterior. Naturalmente, a adaptação das tecnologias às condições locais, bem como seu aprimoramento, também estava na ambição do programa. 
Além disso, dois efeitos do programa foram destacados tanto nas justificativas oficiais do Paiss quanto nos documentos de avaliação preliminar do programa (NYKO et al., 2013): o incremento da coordenação de ações entre os diferentes atores envolvidos (incluindo Finep, BNDES, empresas e centros de pesquisa); e a integração entre os instrumentos de apoio disponibilizados pelas principais agências federais. Como reflexo desta maior coordenação, e da oportunidade percebida pelo setor privado, o Paiss representou um incremento significativo na carteira de projetos inovadores do BNDES e da Finep, relacionados ao setor de açúcar e álcool.

Desse modo, o Paiss significou um grande avanço na abordagem de apresentação, seleção e construção do apoio público a projetos no Brasil. Seu objetivo principal seria, portanto, o aprimoramento institucional, uma vez que o modus operandi inovador estabelecido pelo programa foi o grande diferencial de sucesso. Além disso, naturalmente, o programa visava dar maior publicidade às oportunidades de aproveitamento de resíduos ao setor sucroalcooleiro nacional.

\subsection{Processos de formulação dos programas, seleção e acompanhamento de projetos}

Nesta seção, é analisada a dimensão dos processos conduzidos pelas agências executoras dos programas, de acordo com a proposta do quadro analítico (Quadro 1). Os processos são agrupados em três grandes fases: formulação do programa; seleção dos projetos para apoio; e acompanhamento dos projetos apoiados.

\section{Formulação do programa}

A fase de formulação do programa foi aqui analisada a partir de dois aspectos: profundidade do diagnóstico tecnológico e envolvimento da comunidade científica.

\section{Nivel de aprofundamento tecnológico}

No contexto deste artigo, o termo "nível de aprofundamento tecnológico" não se refere às qualidades tecnológicas dos projetos apoiados, mas sim aos processos instaurados nas agências responsáveis pela formulação dos programas para análise dessas tecnologias.

Entre os três programas analisados, observa-se que o Biomass Program apresenta maior esforço de mapeamento tecnológico por parte dos seus gestores. Em primeiro 
lugar, o estabelecimento de indicadores e metas claras, impostas pelo BETO a si próprio, confere a suas rotinas de trabalho um alto nível de pragmatismo. Como exemplo de metas definidas pelo BETO, cita-se o custo de conversão de US $\$ 1,83$ por galão de bio-óleo até 2017 , ou a produção de 80 milhôes de galóes de combustíveis avançados até 2014 (BETO MYPP, 2013).

Em seguida, a construção dos design cases, ${ }^{2}$ com forte apoio da equipe de pesquisadores do National Renewable Energy Laboratory (NREL), ${ }^{3}$ aporta à etapa de formulação de grande conteúdo de engenharia de processos. Ferramentas comumente usadas por empresas especializadas em engenharia de processos para projetar processos industriais, como elaboração de fluxogramas, balanços de massa e energia, modelagem e simuladores computacionais, são incorporadas às rotinas de formulação de programas. Com isso, os editais já identificam os gargalos tecnológicos a serem superados nos principais processos e operaçôes unitárias objeto de apoio, transmitindo uma mensagem clara à comunidade científica e empresarial interessada em se candidatar ao programa de apoio.

O NER300 apresenta o nível intermediário de aprofundamento tecnológico. A identificação, no edital, das diversas subcategorias passíveis de apoio reflete o esforço de mapeamento das tecnologias e rotas mais promissoras para cada fonte de energia renovável, embora não se encontrem evidências de comparações de cenários baseadas em simulação computacional de processos, como no caso do programa norte-americano.

O Paiss fica no nível mais baixo de aprofundamento tecnológico na fase de formulação. Conforme discutido anteriormente, o foco principal da etapa de formulação do desse programa foi a identificação e a solução de lacunas institucionais, em particular a carência de coordenação de esforços e a integração de instrumentos de apoio. Ainda assim, a Linha 1 do Paiss (etanol de segunda geração) apresentou o conjunto de tecnologias que deveriam compor um plano de negócio submetido para apoio, no caso das rotas biotecnológicas. Ademais, como o objetivo do programa não foi disparar uma corrida tecnológica aos moldes do conceito de "projetos orientados a missões", com indicadores e metas bem estabelecidos, como nos casos dos EUA e da Comunidade Europeia, pode-se dizer que o nível de aprofundamento tecnológico da sua fase de formulação está aderente às suas intenções.

2 Design cases são estudos de engenharia que, assumindo uma rota tecnológica proposta para conversão de biomassa em bioprodutos, avaliam fatores técnicos e econômicos e apontam os gargalos a serem superados para que a referida rota seja viável. Os design cases são disponibilizados publicamente pelo Departamento de Energia dos EUA.

3 NREL é o principal laboratório nacional, ligado ao Departamento de Energia dos EUA, para estudos de energia renovável e eficiência energética nos EUA. 
Nivel de envolvimento da comunidade cientifica na fase de formulaçãó ${ }^{4}$

Novamente, o Biomass Program se destaca neste quesito de avaliação, uma vez que conta com a dedicação da equipe do NREL, que, na prática, é coautor do conteúdo técnico do programa norte-americano. Outra característica marcante do seu processo de formulação refere-se às constantes request of information (RI), que sistematizam a participação da comunidade interessada, sobretudo de cientistas, por meio de consultas a premissas tecnológicas que serão posteriormente utilizadas para definir o conteúdo de um edital. Com isso, o BETO promove a validação de suas propostas tecnológicas no meio científico interessado.

Já a formulação do NER300 contou com o típico processo de Impact Assessment (IA) efetuado pela Comissão Europeia ao propor qualquer iniciativa de política pública. Esta avaliação de impactos do futuro programa - conduzida por um grupo interno independente da Comissão -, uma versão da proposição e seu racional de intervenção (greenpaper) são submetidos à consulta pública. A proposta foi, portanto, sistematicamente colocada à disposição de debate com a comunidade interessada, incluindo membros da academia. No entanto, não se observam evidências de contribuição direta de um grupo de cientistas na formulação, como no caso do NREL ao Biomass Program.

Já no Paiss, a formulação levou em consideração a opinião de cientistas, especialmente do grupo de pesquisa ligado ao Laboratório Nacional de Ciência e Tecnologia do Bioetanol (CTBE), em Campinas. No entanto, tal participação se deu por meio de entrevistas realizadas pela equipe técnica diretamente envolvida na formulação, da Finep e do BNDES, não representando opiniōes formalizadas. $\mathrm{Ou}$ seja, embora a comunidade científica do país tenha dado relevantes contribuições ao programa, esta consulta foi feita de modo informal e não sistemático.

\section{Seleção de projetos}

Após a formulação, os programas entram na fase de seleção de projetos apoiados. O quadro analítico proposto inclui duas dimensōes que ajudam a compreender os mecanismos usados no processo seletivo: os quesitos classificatórios dos projetos e o nível de profundidade da avaliação tecnológica empreendido pela equipe seletora.

4 Neste artigo, o termo comunidade científica denota o conjunto de pesquisadores, desde a pesquisa básica até o P\&D aplicado a atividades industriais. 


\section{Quesitos classificatórios de projetos}

Neste tópico, serão comparados os critérios usados para formação do ranking de projetos meritórios da subvenção ou grant. Naturalmente, além dos quesitos classificatórios, cada programa estabeleceu um conjunto de quesitos eliminatórios, que se concretizam nas diferentes condiçôes de elegibilidade, como porte mínimo dos projetos (de R 1 milhão, no caso do Paiss, ou de $40 \mathrm{kt} /$ ano de produção, para algumas subcategorias do NER300), capacidade financeira e de gestão do postulante, entre outras. No entanto, são os quesitos classificatórios que, após aplicadas as condiçôes básicas de elegibilidade, elencam os projetos em uma ótica de prioridade de apoio. São eles que materializam, portanto, da forma mais direta, a concorrência pelo recurso público. Em última análise, os critérios classificatórios denotam a visão dos gestores dos programas acerca do tipo de corrida que se deseja estimular e influenciam a eficácia desta tentativa.

Encontram-se na literatura especializada argumentos favoráveis ao design de programas orientados a missões, que têm como características a definição de objetivos específicos e metas claras a serem alcançadas pelos postulantes, no intuito de romper uma fronteira tecnológica bem caracterizada (FORAY et al., 2012). Programas públicos com critérios heterogêneos no nível tecnológico podem influenciar a extensão na qual os subsídios estimulam o investimento privado em $\mathrm{P} \& \mathrm{D}$, sendo relevante considerar o "design" específico do programa de apoio para medir sua efetividade (CLAUSEN, 2009).

Entre os programas estudados, observa-se que em todos os casos foram estabelecidos critérios classificatórios para concessão da subvenção econômica ou grant. No Biomass Program e no NER300, pode-se verificar que os critérios foram objetivos, com indicadores quantitativos. Já no Paiss, os critérios utilizados para alocação da subvenção foram subjetivos, uma vez que refletem a percepção qualitativa dos integrantes do grupo de seleção para atributos intangíveis dos projetos concorrentes (como grau de inovação e de risco, externalidades e grau de nacionalização da tecnologia).

O Biomass Program é o que apresenta maior nível de sofisticação e complexidade na definição dos critérios classificatórios de projetos. Conforme visto anteriormente, sua formulação investiga os gargalos tecnológicos a serem superados em cada pacote relevante de processo, com base nos design cases. Assim, os critérios classificatórios, além de objetivos, são heterogêneos, pois dependem do tipo de processo que se está apoiando. Ressalte-se que a definição de critérios heterogêneos de classificação, bem como a calibração das metas a serem perseguidas em cada um destes indicadores, 
não é uma tarefa trivial. É necessário intenso esforço de pesquisa e de engenharia, na fase de formulação, que precede o lançamento da chamada pública. Este esforço inclui a "arte" de se definirem parâmetros de desempenho que reflitam de maneira acurada o gargalo tecnológico, e, em consequência, sejam atribuídas aos projetos metas desafiadoras, porém factíveis.

O NER300 optou por conceber seus critérios classificatórios com base no custo por desempenho unitário (CPUP), o qual reflete os custos adicionais previstos, por unidade de energia gerada, da adoção de uma nova tecnologia, em relação a uma instalação de referência com tecnologias tradicionais. Ressalte-se que, apesar de o CPUP ser aplicado a todo o grupo de energias renováveis (RES) do programa, a competição foi formulada de modo que os projetos concorram apenas com aqueles da sua subcategoria tecnológica. Ou seja, neste caso, a competição imposta aos projetos candidatos, ainda que objetiva, não se baseou em um quesito tecnológico, mas sim em um diferencial de custos previstos. Portanto, a corrida intencionada foi no sentido de redução do custo total de uma rota, e não individualizada por processo unitário como a escolha do modelo norte-americano.

Já no que se refere ao Paiss, os critérios utilizados para indicação de subvenção econômica aos planos de negócio foram: grau de inovação e risco tecnológico; externalidades da tecnologia; e grau de nacionalização da tecnologia. Ressalte-se que, neste caso, os projetos receberam pontuação de 1 a 3 para cada um dos critérios. Os projetos que obtiveram média aritmética superior a 2 foram habilitados a enviar proposta de subvenção econômica para análise na Finep, desde que satisfeitas as demais condiçôes previstas na chamada pública. Projetos que são essencialmente de infraestrutura física e/ou de porte industrial não foram pontuados, sendo classificados como N.A. (não se aplica).

Destaca-se que, no caso do programa brasileiro, apesar de formalmente definidos como critérios "que habilitam os postulantes a enviarem proposta de subvenção econômica para análise da FINEP”, diferindo do conceito classificatório, na prática estas foram as diretrizes apontadas pelo programa para alocação do instrumento de apoio. Ou seja, na visão do público interessado, a corrida pelo recurso público mais desejado - a subvenção econômica - se deu em função destes parâmetros.

Embora tenham sido definidos os conceitos e criada uma escala de pontuação (de 1 a 3) para cada um dos quesitos, a abordagem é essencialmente subjetiva. Ainda que os avaliadores públicos, com base nos projetos habilitados a envio da proposta, considerassem outros quesitos para seleção final dos projetos apoiados com subvenção, isso tenderia a aumentar ainda mais o nível de subjetividade. Cabe 
destacar, ainda, a característica homogênea destes critérios, uma vez que podem ser aplicados para seleção de projetos em programas direcionados a qualquer setor, de forma mais ou menos horizontal.

\section{Nivel de profundidade da avaliação tecnológica}

Neste quesito, o NER300 é o programa que mais se destaca. Seu processo seletivo estabeleceu como requisitos o envio de documentação de engenharia que demonstrasse o grau de maturidade do projeto. Trata-se de um pacote de documentos típicos de engenharia de processos, como process flow diagrams, balanços de massa e energia, folhas de dados de equipamentos, entre outros.

Além disso, as planilhas de estimativa de custos (investimentos e despesas) requerem do postulante a abertura de cada componente dos custos relevantes, justificando-os. Os documentos de Impact Assessment (IA) referem-se aos requisitos de estudos de Front End Engineering Design (FEED), como forma de tornar os orçamentos mais robustos e mitigar suas incertezas na faixa de $10 \%$. Ou seja, o NER300 previu um conjunto extenso de documentos comprobatórios, pelo postulante, da qualidade da engenharia dos projetos apresentados.

O Biomass Program apresenta nível intermediário neste quesito. Embora composto por equipe de especialistas, muitos dos quais regressos de empresas de engenharia, o BETO não pode contar com suporte do NREL, impedido por potencialmente poder participar dos pleitos de apoio. Ademais, não é uma prática corrente, até o momento, a condução de investigações de due diligence tecnológica, mesmo em projetos de maior porte, embora o órgão esteja considerando realizá-la em breve.

No caso do Paiss, pode-se dizer que a auditoria tecnológica é virtualmente inexistente. A apreciação dos projetos é feita de modo mais holístico, considerando as capacitações gerenciais, financeiras e o histórico de atividades de pesquisa e desenvolvimento do postulante. Novamente, a opção de dar maior ênfase à estratégia do negócio do que ao conteúdo de engenharia dos projetos apresentados é um reflexo natural dos objetivos do programa, que não vislumbrava disparar - e, portanto, não precisaria se certificar sobre - uma corrida tecnológica.

\section{Acompanhamento de projetos}

Após a seleção dos projetos a serem apoiados pelo programa, os mesmos são executados pelas organizaçóes beneficiárias dos recursos públicos. Os processos de 
acompanhamento, por parte dos representantes da administração pública, foram aqui analisados a partir do foco dado às rotinas de acompanhamento.

\section{Foco das rotinas de acompanhamento e avaliação}

A maior intensidade de atuação na fase de acompanhamento ocorre no Biomass Program. A equipe técnica do BETO atua como cogestora dos projetos apoiados. A condução do acompanhamento inclui contatos semanais e reuniôes mensais de acompanhamento do progresso técnico, sendo que a parte administrativa de comprovação de gastos (paperwork, na sua linguagem) é delegada para uma equipe de suporte. Assim, os técnicos são incentivados a participarem dos projetos apoiados de modo a contribuírem para o gerenciamento da qualidade, do prazo, do custo, do escopo e do monitoramento de riscos, juntamente com seus idealizadores e beneficiários do recurso público.

Como os contratos do BETO, em geral, definem metas claras a serem atingidas em cada projeto, a tarefa de acompanhamento fica mais orientada e pragmática. Além disso, como é possível interromper o apoio pelo não cumprimento de metas tecnológicas previamente acordadas, conforme discutido anteriormente, a opinião dos técnicos do BETO tende a ser considerada pela equipe da empresa. Ou seja, o fato de o tipo de apoio conter a modalidade reward for performance cria uma atmosfera mais colaborativa, com aumento da barganha para a opinião dos técnicos do governo. Na realidade, o BETO posiciona-se como copatrocinador do projeto e, como tal, se permite e se habilita a executar funções de gerenciamento do projeto, em uma postura ativa.

Nos casos do NER300 e do Paiss, ainda é prematuro avaliar as rotinas de acompanhamento, uma vez que poucos projetos entraram na fase de execução. No entanto, com base nas evidências encontradas até o momento e nas experiências de acompanhamento em outros programas executados pelos mesmos órgãos, podem ser elaborados alguns comentários.

O NER300 apresenta uma estrutura compartilhada de acompanhamento. A coordenação geral, as definições dos fluxos de informação e as diretrizes para os informes que devem ser prestados ficam a cargo da Comissão Europeia. Já o acompanhamento individual de cada projeto foi delegado à equipe do país-membro, que em seguida submete relatórios de progresso para a Comissão. Tipicamente, a Comissão Europeia realiza avaliação dos seus programas de apoio, o que leva a crer que não será diferente no caso do NER300. 
Já no Paiss o acompanhamento será, assim como nos demais projetos apoiados via subvenção, voltado para o monitoramento do plano de trabalho pela equipe própria da Finep. Não há, neste caso, interferências no processo decisório ou na condução técnica do projeto, embora os recursos públicos alcancem fatia significativa dos projetos apoiados.

É intuitiva a correlação deste modo de acompanhamento com o nível de aprofundamento tecnológico nas fases de formulação e seleção, em geral baixo, se comparado com os dois outros programas analisados. Sobretudo diante de um mecanismo essencialmente cost-sharing e da subjetividade do processo seletivo, é natural esperar que o acompanhamento não se proponha a interferir na condução dos projetos. Caso contrário, correria o risco de se tornar arbitrário.

Os documentos de avaliação do Paiss produzidos até o momento demonstram, de forma agregada e sem identificar os projetos apoiados, os efeitos da iniciativa de fomento (NYKO et al., 2013). Atendendo ao diagnóstico elaborado durante a fase de formulação do programa, a avaliação considera que o Paiss foi uma iniciativa de sucesso, na medida em que ajudou a reduzir as deficiências de coordenação entre agências de promoção ao desenvolvimento e atores locais interessados em se engajar em atividades de P\&D voltadas aos biocombustíveis e bioprodutos.

\section{Conclusões}

O presente artigo se propôs a estudar três casos de instrumentos de apoio público direto disponíveis para as empresas interessadas em desenvolver novas rotas tecnológicas para produção de biocombustíveis avançados e produtos químicos a partir de fontes renováveis. Os casos escolhidos para estudo foram: o Biomass Program, nos EUA, o Paiss, no Brasil, e o NER300, na Europa.

Por um lado, pode-se destacar o avanço que o Paiss representou na condução do incentivo público a atividades de P\&D no setor de biocombustíveis no Brasil. A coordenação entre as duas principais agências federais de fomento - Finep e BNDES -, a integração de diversos instrumentos financeiros em um único programa e a mobilização orçamentária com foco temático permitiram alavancar investimento privado em P\&D no setor. Por outro lado, a experiência internacional aponta para opçôes ainda pouco exploradas pela política pública brasileira.

Pode-se dizer que o programa norte-americano se enquadra na categoria de projetos (nacionais) orientados à missão, com metas específicas definidas e lançadas aos postulantes privados. Seus processos de formulação do programa, bem como 
os de seleção e acompanhamento dos projetos, denotam a grande capacidade do governo daquele país em disparar uma corrida tecnológica.

Este modus operandi da agência dos EUA, com grande enfoque pragmático e voltado ao cumprimento de metas estabelecidas pelo próprio governo, abre a possibilidade para reflexão dos formuladores de políticas públicas brasileiras que visam incentivar o P\&D privado no país. Para isso, no setor estudado, seria necessário ampliar o conteúdo de engenharia aportado nos processos de formulação de programas de apoio. Naturalmente, estudos em outros programas de apoio a tecnologias em diferentes setores poderiam corroborar ou confrontar esta ideia.

Os mecanismos de recompensa percebidos no programa europeu também apontam para uma opção não vislumbrada no Brasil até o momento. A despeito da disponibilidade orçamentária, consideravelmente maior nos EUA e na Comunidade Europeia, poderia ser avaliada a criação de mecanismos com característica de recompensas, de modo a complementar os instrumentos já existentes no país. Esta modalidade torna imprescindível, no entanto, um mapeamento tecnológico mais exigente e a predefinição de indicadores de desempenho e metas. Novamente, torna-se necessário massificar os programas públicos com disciplinas de engenharia.

Destaque-se, ainda, que os programas norte-americano e europeu respondem a um planejamento estratégico definido por políticas públicas previamente formuladas e em execução. Nos EUA, tal planejamento se concretiza principalmente pelo RFS, que estabelece metas mandatórias e crescentes para uso de biocombustíveis de alto desempenho. Na Europa, o planejamento supranacional inclui o EU Climate Energy Package. Desse modo, tanto o Biomass Program quanto o NER300 se propõem a contribuir para a viabilização do plano estratégico nacional (EUA) ou regional (Comunidade Europeia). Já no caso brasileiro, não se verifica um plano estratégico nacional de médio prazo que tenha balizado ou mesmo motivado a formulação do Paiss.

A experiência internacional também indica uma cooperação mais extensa, sistemática e formal com a comunidade de consultores externos e institutos de pesquisa, em comparação com o que vem sendo praticado no Brasil. Nos EUA, o NREL participa ativamente do processo de formulação do Biomass Program. Na Europa, a contratação de empresas de engenharia para realização de auditorias tecnológicas corrobora a compreensão dos riscos e gargalos dos projetos apoiados pelo NER300. No Brasil, uma aproximação institucional entre os agentes de fomento e institutos nacionais de pesquisa, como a Embrapa e o Centro de Tecnologia do Bioetanol (CTBE), poderia ser explorada. 
A subvenção econômica à inovação no Brasil é um instrumento muito poderoso de política pública, mas ainda recente se comparada com os outros casos estudados. É natural, portanto, que o instrumento seja continuamente aprimorado. Este trabalho teve como objetivo contribuir para a reflexão acerca do seu aperfeiçoamento, indicando que o mero incremento orçamentário pode não ser fator suficiente para se alcançar a efetividade desejada. Foco de atenção deve ser dado às rotinas de formulação dos programas, seleção e acompanhamento dos projetos, por parte da administração pública.

\section{Referências bibliográficas}

ARROW, K. J. Economic welfare and the allocation of resources for inventions. National Bureau of Economic Research. The rate and direction of inventive activity: economic and social factors. Princeton: Princeton University Press, 1962, p. 609-626.

BETO Integrated Biorefineries. Disponível em: <http://www1.eere.energy.gov/bioenergy/ printable_versions/integrated_biorefineries.html>. Acesso em: 30 jun. 2013.

BETO MYPP. Bioenergy Technologies Office. Multi-year program plan. US Department of Energy, May 2013. Disponível em: <www.eere.energy.gov/bioenergy/pdfs/mypp_may_2013. pdf>. Acesso em: 25 set. 2013.

BUSOM, I.; FERNÁNDEZ-RIBAS, A. The impact of firm participation in R\&D programmes on R\&D partnership. Research Policy, n. 37, p. 240-257, 2008.

CANTNER, U.; KÖSTERS, S. Picking the winner? Empirical evidence on the targeting of R\&D subsidies to start-ups. Small Bus Econ, n. 39, p. 921-936, 2012.

CLARYSSE, B.; WRIGHT, M.; MUSTAR, P. Behavioural additionality of R\&D subsidies: a learning perspective. Research Policy, v. 38, n. 10, p. 1517-1533, 2009.

CLAUSEN, T. H. Do subsidies have positive impacts on R\&D and innovation activities at the firm level? Structural Change and Economic Dynamics, v. 20, n. 4, p. 239-253, 2009.

COMISSÃO EUROPEIA. Disponível em: <http://ec.europa.eu/about/index_pt.htm>. Acesso em: 25 set. 2013.

CZARNITZKI, D.; LOPES-BENTO, C. Value for money? New microeconometric evidence on public R\&D grants in Flanders. Research Policy, v. 42, n. 1, p. 76-89, 2012.

DAVID, P.; HALL, B. H.; TOOLE, A. A., Is public R\&D a complement or substitute for private R\&D? A review of the econometric evidence. Research Policy, n. 29, p. 497-529, 2000. 
FORAY, D.; MOWERY, D. C.; NELSON, R. R. Public R\&D and social challenges: What lessons from mission R\&D programs? Research Policy, v. 41, n. 10, p. 1697-1702, 2012.

GONZÁLEZ, X.; PAZÓ, C.. Do public subsidies stimulate private R\&D spending? Research Policy, v. 37, n. 3, p. 371-389, 2008.

GRANTS.COM. Disponível em: <www.grants.com>. Acesso em: 15 abr. 2013.

GRETZ, R.; HIGHFILL, J.; SCOTT, R. C. R\&D subsidy games: a cost sharing approach vs. reward for performance. Journal Technology Transfer, v. 37, n. 4, p. 385-403, 2012.

GUISADO-GONZÁLEZ, M.; GUISADO-TATO, M.; VILA-ALONSO, M. Using public aid programs to finance innovation in multi-level governance systems. Transylvanian Review of Administrative Science, n. 38, p. 61-78, 2013.

LAINCZ, C. R\&D subsidies in a model of growth with dynamic market structure. $J$ Evol Econ, n. 19, p. 643-673, 2009.

NYKO, D.; GARCIA, J. L. F.; MILANEZ, A. Y.; DUNHAM, F. B. A corrida tecnológica pelos combustíveis de segunda geração: uma perspectiva comparada. BNDES Setorial, n. 32, p. 5-48, 2010.

NYKO, D.; VALENTE, M. S.; DUNHAM, F. B.; MILANEZ, A. Y.; COSTA, L. M.; PEREIRA, F. S.; TANAKA, A. K. R.; RODRIGUES, A. V. P. Planos de fomento estruturado podem ser mecanismos mais eficientes de política industrial? Uma discussão à luz da experiência do PAISS e seus resultados. BNDES Setorial, n. 38, p. 5-48, 2013.

PAISS CHAMADA PÚBLICA. 2011. Disponível em: <http://www.finep.gov.br/editais/ encerrados.asp>. Acesso em: 25 set. 2013.

PEREIRA, F. dos S. Comparação internacional de programas de subvenção a atividades de PD\&I em biocombustíveis. Dissertação (Mestrado). Rio de Janeiro: UFRJ, Escola de Química, 2013.

STEINMUELLER, W. E. Economics of technology policy. In: HALL, B.; ROSENBERG, N. (Eds.). Handbooks in economics of innovation. Amsterdã: Elsevier, v. 2, 2010.

WANZENBÖCK, I.; SCHERNGELL, T.; FISCHER, M. M. How do firm characterisctics affect behavioural additionalities of public R\&D subsidies? Evidence for the Austrian transport sector. Technovation, n. 33, p. 66-77, 2012. 